\title{
ORIGINAL
}

\section{Usefulness of blood flow evaluation by indocyanine green fluorescence system in laparoscopic anterior resection}

\author{
Jun Higashijima, Mitsuo Shimada, Kozo Yoshikawa, Tomohiko Miyatani, Takuya Tokunaga, Masaaki Nishi, \\ Hideya Kashihara, and Chie Takasu \\ Department of Surgery, Institute of Health Biosciences, the University of Tokushima, Japan
}

\begin{abstract}
Background: One of the major cause of anastomotic leakage (AL) in anterior resection of the rectum is insufficient blood flow of the remnant colon. The indocyanine green fluorescence system (ICG-FS) can visualize the blood flow of organs intra-operatively. The aim of this study is to investigate the usefulness of ICG-FS for evaluating the blood flow of the remnant colon in laparoscopic anterior resection. Materials and Methods: Rectal cancer patients $(n=24)$ who underwent laparoscopic anterior resection were included in this study. After resection of the rectum, 7.5mg of ICG was administered intravenously, and the blood flow of the oral stump was evaluated by the ICG-FS. The relationship between the fluorescence time (FT) of the oral stump and AL was investigated retrospectively. Result: Two of twenty-four patients (8.3\%) suffered AL. The FT of these two cases were over 60 seconds. In the case with the FT was over 80 seconds, we performed additional resection of the late fluorescence portion of the remnant colon and could avoid AL. In patients whose FT was under 60 seconds, no patients suffered AL. Conclusion: ICG-FS may be useful for evaluating the blood flow of the remnant colon to avoid $A L$ in laparoscopic anterior resection. J. Med. Invest. 66 : 65-69, February, 2019
\end{abstract}

Keywords : blood flow evaluation, indocyanine green (ICG) fluorescence system, laparoscopic anterior resection

\section{INTRODUCTION}

Anastomotic leakage (AL) is still one of the serious and lifethreatening complications in anterior resection for rectal cancer. In rectal surgery, it is reported that the incidence of $\mathrm{AL}$ is from $3.6 \%$ to $11.6 \%(1-3)$. It has been reported that AL significantly increases the local recurrence rate and reduces long-term cancer specific survival in colorectal cancer patients (4). And elderly patients especially have a higher mortality risk related to AL (5).

Many factors that increase the incidence of AL have been reported, such as : low anastomoses, tumor size, gender (male), smoking, alcohol abuse, and pre-operative malnutrition (6,7). As well, the visceral fat area is an important predictive factor for $\mathrm{AL}$ (8). Regarding the surgical technique, multiple stapler firings used for resection of the rectum was significantly associated with AL after laparoscopic anterior resection (9). To avoid AL, some strategies were considered. For example, a trans-anal drain (10), and precompression before stapler firing (7).

Same as these risk factors, the blood flow of the remnant colon is the major course of AL. To maintain the blood flow of the colon, pre-operative evaluation of the patient's mesenteric vascular anatomy is very important. The multidetector-row computed tomography (MDCT) and three-dimensional reconstruction of mesenteric vessels have been shown to be effective for evaluation of mesenteric vascular variations before laparoscopic surgery $(11,12)$. Pre-operative MDCT is useful to understand the vascular anatomy, but is not enough to secure blood flow of the colon because it is unclear whether the ideal blood flow of the remnant colon is acquired by the planned resection of vessels. Therefore evaluation of the intra-

Received for publication June 15, 2018 ; accepted July 25, 2018.

Address correspondence and reprint requests to Jun Higashijima, Department of Surgery, the University of Tokushima, 3-18-15 Kuramotocho, Tokushima. 770-8503 Japan and Fax : +81-88-631-9698. operative blood flow is necessary.

Until now, laser doppler flowmetry and thermography have been used as intra-operative blood flow evaluation devices. For example, laser doppler flowmetry is reported as a feasible method to evaluate the ischemia of the intestine $(13,14)$ and thermography has reported to be useful for evaluating the gastric vascularization and gastric tube viability during esophagectomy (15).

The hyper eye medical system (HEMS), (Mizuho Medical Co.,Ltd. Tokyo, Japan) is the indocyanine green (ICG) fluorescence imaging system (ICG-FS) which can visualize the blood vessels and lymphatic vessel by the near-infrared light of 760-780 nm. ICG , when injected intravenously, emits light with a peak wave length of 800-850 nm and clearly visualizes blood vessels and lymphatic vessels.

The ICG-FS has been used as a real-time identification device for cancers. It has been used to detect the sentinel lymph nodes in breast cancer (16) ; esophageal cancer $(17)$; gastric cancer $(18,19)$; and lung cancer (20). In HCC or liver tumor, intra-operative ICG fluorescence imaging has been used as a sensitive identification device (21-23). In colon cancer, ICG-FS has been used as a useful colonic marking device for early colon cancer or colon adenoma patients (24). As well, it is also reported that the detection of lateral sentinel nodes in lower rectal cancer by the ICG-FS may be useful for determining the indications for performing lateral pelvic lymph node dissection (25). The ICG -FS has also been used in nonmalignant diseases. It is reported that HEMS has been useful during surgery for a patient with non-occlusive mesenteric ischemia (26). In cardiovascular surgery, HEMS is reported as a useful device for intra-operative graft assessment $(27,28)$. Therefore, the ICG-FS is a very useful intra-operative device which can evaluate real-time blood flow of various organs.

There are few reports about the intra-operative blood flow evaluation of the colon. We hypothesized that the intraoperative bloodflow evaluation of the remnant colon by ICG-FS may be useful to predict and avoid anastomotic leakage. The aim of this study is to evaluate the usefulness of the HEMS for evaluating the 
intra-operative blood flow of the remnant colon to avoid AL.

\section{PATIENTS AND METHODS}

This study included twenty-four patients who underwent laparoscopic anterior resection for rectal cancer at Tokushima University Hospital between 2012 and 2013. Patients' characteristics are shown in Table 1. After resection of the rectal cancer, $7.5 \mathrm{mg}$ of ICG (Diagnogreen ; Daiichi Sankyo Co.,Ltd., Tokyo, Japan) was administered intravenously, and the blood flow of the oral stump was evaluated using HEMS intraoperatively. After ICG administration, the fluorescent time (FT) of the stump was measured. The FT was defined as the time from ICG injection to the point when the stump was strongly and fully shining in the monitor. Then end to end anastomosis was performed by double stapling technique. Diverting stoma was not performed in all cases. The relationship between the FT of the oral stump and AL was investigated retrospectively.

\section{Statistical Analysis}

In comparison of the two groups, the Student's t-test and chisquared test were applied for categorical data. The results are presented as mean \pm SD. All statistical analysis was performed using the JMP 10 statistical software package (SAS Institute Inc, Tokyo, Japan). A p-value less than 0.05 was considered statistically significant.

\section{RESULTS}

Figure 1 shows the real fluorescence images of anal stumps. These images show that the oral stump was gradually fluorescent time dependently and fully fluorescent at forty-five seconds (sec).

The FT of all cases are shown in Figure 2. The median time was $46 \mathrm{sec}$. In the over $60 \mathrm{sec}$ cases, AL happened in the 62 and $71 \mathrm{sec}$ cases. In the over $60 \mathrm{sec}$ cases, excluding the $80 \mathrm{sec}$ case with additional resection of the remnant colon, the $\mathrm{AL}$ rate $(50 \%)$ increased compared with under $60 \mathrm{sec}$ cases. Under $60 \mathrm{sec}$ cases, there were no AL cases. $60 \mathrm{sec}$ may be a clear cut off point to judge whether $\mathrm{AL}$ will happen or not.

The one AL case is shown in Figure 3. In this case, the oral stump was gradually fluorescent time dependently and the FT was 71 sec. Two days after operation, AL happened and the patient needed peritoneal lavage and drainage and ileostomy. Colon fiber showed the necrotic area of the anal stump clearly. After six months, the necrotic area improved and the ileostomy was closed.

One suggestive case is shown in Figure 4. In this case, the oral stump was gradually fluorescent time dependently and the blood

Table 1. Patients' characteristics

\begin{tabular}{lc}
\hline \multicolumn{1}{c}{ Variables } & $(\mathrm{n}=24)$ \\
\hline Sex (male : female) & $18: 6$ \\
Age (years) & $62(45-80)$ \\
Operation time (minutes) & $281(141-481)$ \\
Blood loss (ml) & $20(10-750)$ \\
Tumor location (upper/lower) & $21 / 3$ \\
Stage (I/II/III/IV) & $6 / 7 / 7 / 3^{\star}$ \\
Resection of vessels & \\
(root of IMA : LCA preserved) & $7: 17$ \\
Average hospital stay (days) & $21(10-82)$ \\
\hline
\end{tabular}

\footnotetext{
* one patient is carcinoid
}

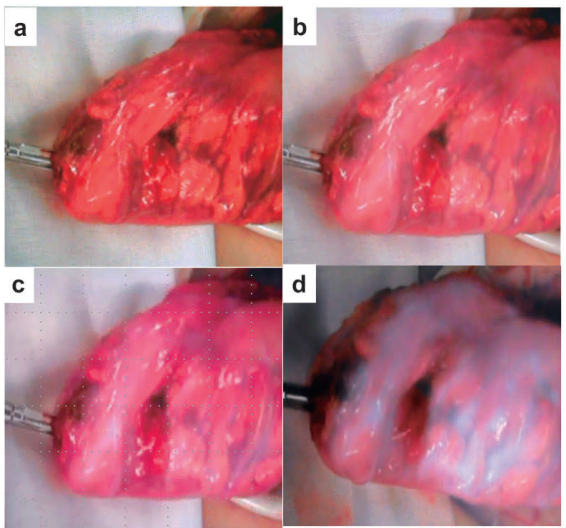

Figure 1. Blood flow evaluation of oral stump of the colon Blood flow was clearly recognized as white lesion by using HEMS. a : 20 sec. b : 25 sec. $c$ : $35 \mathrm{sec}$. $d: 45$ sec. FT of this patient was $45 \mathrm{sec}$.

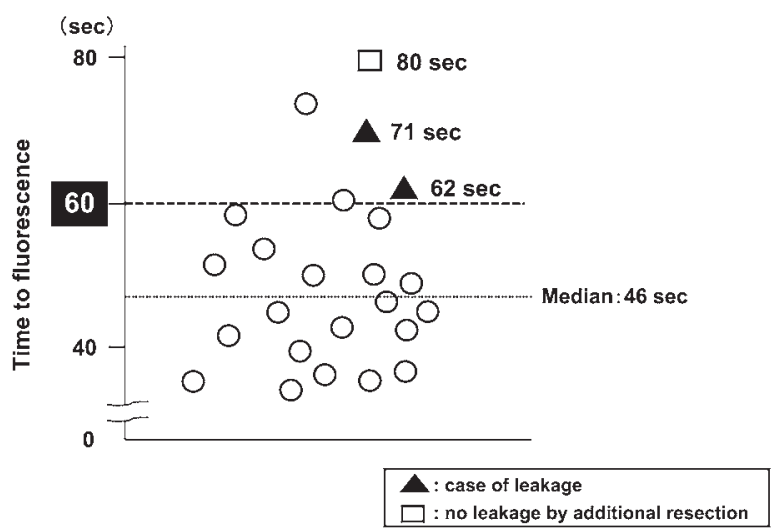

Figure 2. Relationships between $\mathrm{FT}$ and leakage The median was $46 \mathrm{sec}$. Over $60 \mathrm{sec}$ cases, AL rate increased.

flow was clearly visualized, but it was late $(80 \mathrm{sec})$ and over $60 \mathrm{sec}$. Additional resection of the delayed fluorescent area was performed, resulting in the FT improving from 80 to $50 \mathrm{sec}$ and $\mathrm{AL}$ did not happen.

And other useful usage of the HEMS is shown in Figure 5. For example, in the case of colon cancer near the sigmoid-descending (SD) junction, sometimes it may be important problem whether the superior rectal artery (SRA) should be preserved or not. In this case, we evaluated blood flow with clamping of the SRA. Then the FT of the anal stump was $75 \mathrm{sec}$, delayed over $60 \mathrm{sec}$. And partial resection of colon was performed with selective resection of $\mathrm{S} 1$ and S2 preserving SRA. HEMS clearly demonstrated the importance of preserving the SRA in cases of tumors near the SD junction.

In Table 2, the difference of FT by resection point of vessels. There was no significant differences of FT between IMA resection and left colic artery (LCA) preserving group.And there was no significant difference in $\mathrm{AL}$ rate between the two groups. 
HEMS : 71sec

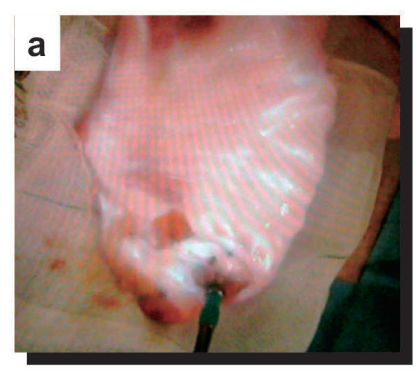

2 days after

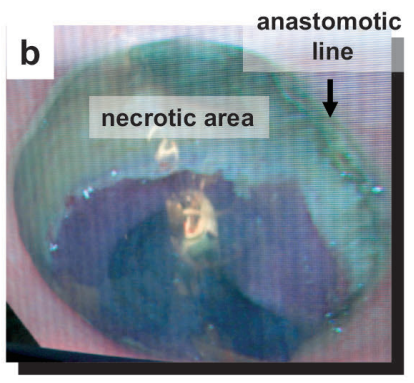

Six months after

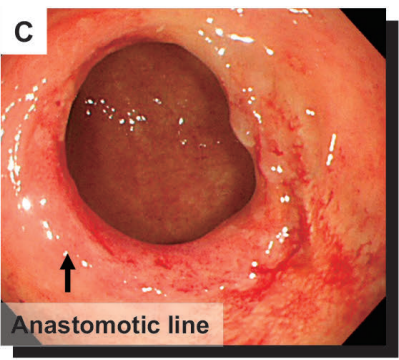

Figure 3. A leakage case with delayed FT a : FT of oral stump was $71 \mathrm{sec}$.

$\mathrm{b}$ : Two days after operation, AL happened. Colon fiber shows the clear images of necrotic area of oral side portion from anastomotic line. c: Six months after operation, colon fiber shows the improvement and cure of AL.
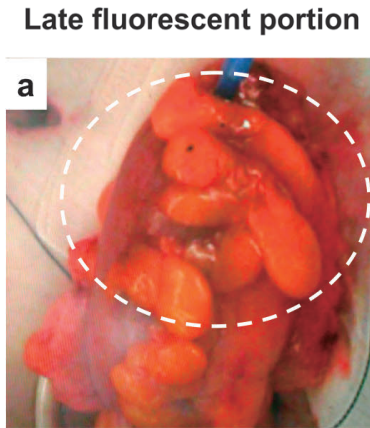

delayed FT : $80 \mathrm{sec}$

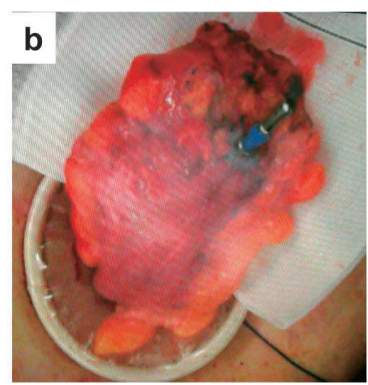

\section{Additional resection}

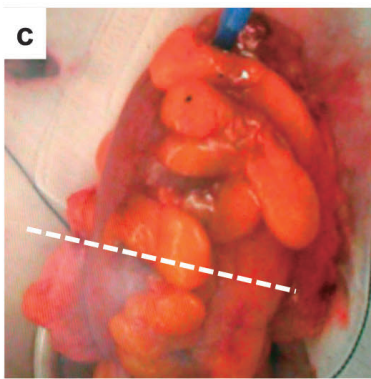

Figure 4. Acase that needs additional resection of remnant colon

a : Oral stump was gradually fluorescent time dependently, but the FT of the top of stump was late.

b : Fully FT of this patient was $80 \mathrm{sec}$.

c: Additional resection of delayed fluorescent portion was performed, and FT was improved from 80 to 50 sec.

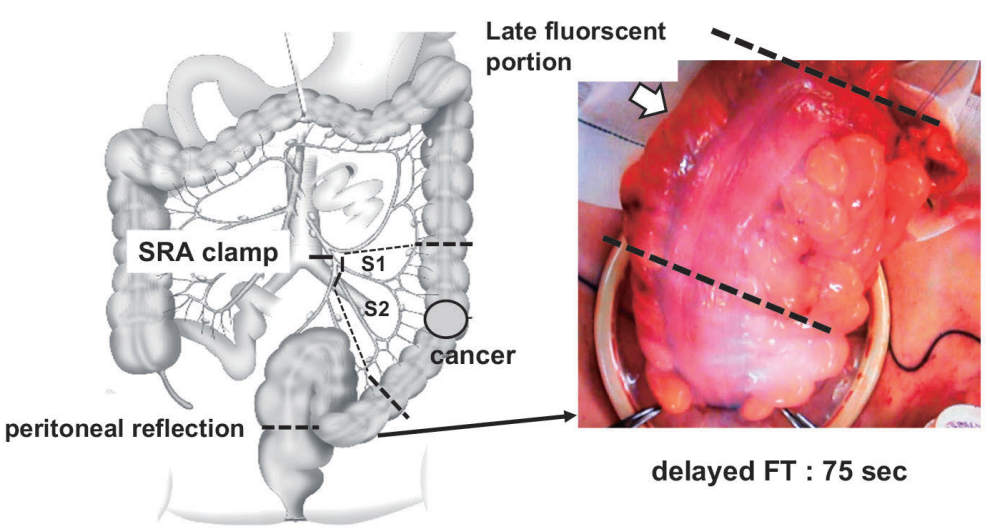

Figure 5. Usefulness of the HEMS for the case of cancer near SD junction

Blood flow was evaluated with clamping SRA. Then the FT of anal stump was $75 \mathrm{sec}$, delayed over $60 \mathrm{sec}$.

Table2. Difference of FT by resection point of vessel

\begin{tabular}{lccc}
\hline & $\operatorname{IMA}(\mathrm{n}=7)$ & $\begin{array}{c}\text { LCA preserved } \\
(\mathrm{n}=17)\end{array}$ & $\mathrm{p}$-value \\
\hline $\begin{array}{l}\text { fluorescenttime } \\
\begin{array}{c}\text { anastomotic } \\
\text { leakage }(-/+)\end{array}\end{array}$ & $42.7 \pm 7.3$ & $49.5 \pm 13.7$ & 0.18 \\
\hline
\end{tabular}

\section{DISCUSSION}

In this study, we used ICG-FS (HEMS) as an intra-operative blood flow evaluation tool and showed that HEMS was a very useful tool to predict and avoid AL.

Blood flow is a very important factor in $\mathrm{AL}$ and may be different depending on the resection point of vessels. There are some reports considering the results of these procedures. If the IMA was ligated at the root, the blood flow of the oral stump depends mainly on the 
middle colic and marginal arteries $(29,30)$. There are some reports that the marginal artery is adequate for preserving the viability of the remaining colon (31-33). However, some reports concluded that IMA ligation significantly reduces the blood flow of the proximal limb $(34,35)$. And it is reported that there was no significant difference in the AL rate between the IMA ligation group and the LCA preserving group (36). Another report concluded that despite the decreased blood flow of the proximal colon after IMA ligation, the effect of SRA ligation concerning blood flow of the anastomotic region has been controversial but it might be obvious in atherosclerotic disease patients (37). In our study, as shown in Table 2, there was no significant difference in the FT and AL rate between the two groups. HEMS may be useful for solving this controversial problem and especially effective in patients with atherosclerotic disease.

HEMS can be used in other situations as shown in Figure 5. For example, when performing a sigmoidectomy for sigmoid colon cancer near the SD colon junction, it is important to consider whether the SRA should be preserved or not to prevent ischemia of the anal side colon. When blood flow evaluation of the colon was performed with clamping the SRA, if we recognize the late fluorescence portion in the anal side colon, we should preserve the SRA. In atherosclerosis patients with diabetes mellitus, smoking, hyper tension etc, blood flow of the colon may be worse than in healthy patients. HEMS may be useful in order to resect blood vessels correctly when operating on these patients with high risk factors.

There are some problems regarding our study. One problem was the objectiveness of the fluorescence timing. In this study, only the FT was measured, but this is dependent on the subjective judgment of the operator. So now we tried to digitize the FT objectively and exactly using some softwares. Another problem was that the blood flow of the anal stump was not evaluated. Blood flow of the anal stump may be also an important factor of anastomotic leakage, so we are now evaluating the blood flow of the anal stump using laparoscopic ICG system. The third problem was that the blood flow was not the only factor affecting anastomotic leakage. In this study, over 60 seconds fluorescent cases, anastomotic leakage rate increased. But there were no leakage cases in under 60 seconds FT cases. When anastomotic leakage happens, several risk factors, as mentioned in the introduction, may be concerned. HEMS is a very useful device, but it may be important to know the limitation. In laparoscopic colectomy and other relevant surgical procedures, it is very important to pay attention to not only the blood flow, but also other risk factors. Another strategy may be needed, for example the predicting formula of AL with combination of FT and risk factors.

In conclusion, the ICG-FS (HEMS) may be useful for evaluating the blood flow of the remnant colon following resection of the rectum. Therefore this system can be used for the estimation of the safety for the anastomosis in laparoscopic anterior resection of the rectum.

\section{ACKNOWLEDGEMENT}

Any financial support was not accepted in this study.

\section{REFERENCES}

1. Akiyoshi T, Ueno M, Fukunaga Y, Nagayama S, Fujimoto Y, Konishi T, Kuroyanagi H, Yamaguchi T : Incidence of and risk factors for anastomotic leakage after laparoscopic anterior resection with intracorporeal rectal transection and doublestapling technique anastomosis for rectal cancer. Am J Surg. 2011 Sep ; 202(3) : 259-64.

2. Park JS, Choi GS, Kim SH, Kim HR, Kim NK, Lee KY, Kang
SB, Kim JY, Lee KY, Kim BC, Bae BN, Son GM, Lee SI, Kang $\mathrm{H}$ : Multicenter analysis of risk factors for anastomotic leakage after laparoscopic rectal cancer excision: the Korean laparoscopic colorectal surgery study group. Ann Surg. 2013 Apr ; 257(4) : 665-71.

3. Peeters KC, Tollenaar RA, Marijnen CA, Klein Kranenbarg E, Steup WH, Wiggers T, Rutten HJ, van de Velde CJ; Dutch Colorectal Cancer Group. : Risk factors for anastomotic failure after total mesorectal excision of rectal cancer. Br J Surg $2005 ; 92: 211-6$.

4. Mirnezami A, Mirnezami R, Chandrakumaran K, Sasapu K, Sagar P, Finan P : Increased local recurrence and reduced survival from colorectal cancer following anastomotic leak: systematic review and meta-analysis. Ann Surg 2011;253:890899

5. Bakker IS, Grossmann I, Henneman D, Havenga K, Wiggers T: Risk factors for anastomotic leakage and leak-related mortality after colonic cancer surgery in a nationwide audit. Br J Surg $2014 ; 101: 424-432$

6. Taflampas P, Christodoulakis M, Tsiftsis DD : Anastomotic leakage after low anterior resection for rectal cancer: facts, obscurity, and fiction. Surg Today $2009 ; 39: 183-188$

7. Kawada K, Hasegawa S, Hida K, Hirai K, Okoshi K, Nomura A, Kawamura J, Nagayama S, Sakai Y : Risk factors for anastomotic leakage after laparoscopic low anterior resection with DST anastomosis. Surg Endosc. 2014 Oct ; 28(10) : 2988-95.

8. Watanabe J, Tatsumi K, Ota M, Suwa Y, Suzuki S, Watanabe A, Ishibe A, Watanabe K, Akiyama H, Ichikawa Y, Morita S, Endo I : The impact of visceral obesity on surgical outcomes of laparoscopic surgery for colon cancer. Int $\mathrm{J}$ Colorectal Dis $2014 ; 29: 343-351$

9. Ito M, Sugito M, Kobayashi A, Nishizawa Y, Tsunoda Y, Saito $\mathrm{N}$ : Relationship between multiple numbers of stapler firings during rectal division and anastomotic leakage after laparoscopic rectal resection. Int J Colorectal Dis. $2008 \mathrm{Jul}$; 23(7) : 703-7.

10. Nishigori H, Ito M, Nishizawa Y, Nishizawa Y, Kobayashi A, Sugito M, Saito N : Effectiveness of a transanal tube for the prevention of anastomotic leakage after rectal cancer surgery. World J Surg. 2014 Jul ; 38(7) : 1843-51

11. Kanamoto T, Matsuki M, Okuda J, Inada Y, Tatsugami F, Tanikake M, Yoshikawa S, Narabayashi I, Kawasaki H, Tanaka K, Yamamoto T, Tanigawa N, Egashira Y, Shibayama $\mathrm{Y}$ : Preoperative evaluation of local invasion and metastatic lymph nodes of colorectal cancer and mesenteric vascular variations using multidetector-row computed tomography before laparoscopic surgery. J Comput Assist Tomogr. 2007 NovDec ; 31(6) : 831-9.

12. Mari FS, Nigri G, Pancaldi A, De Cecco CN, Gasparrini M, Dall'Oglio A, Pindozzi F, Laghi A, Brescia A : Role of $\mathrm{CT}$ angiography with three-dimensional reconstruction of mesenteric vessels in laparoscopic colorectal resections:a randomized controlled trial. Surg Endosc. 2013 Jun ; 27(6) : 205867

13. Redaelli CA, Schilling MK, Büchler MW : Intraoperative laser Doppler flowmetry :

a predictor of ischemic injury in acute mesenteric infarction. Dig Surg. $1998 ; 15(1): 55-9$.

14. Redaelli CA, Schilling MK, Carrel TP. : Intraoperative assessment of intestinal viability by laser Doppler flowmetry for surgery of ruptured abdominal aortic aneurysms. World J Surg. 1998 Mar ; 22(3) : 283-9.

15. Nishikawa K, Matsudaira H, Suzuki H, Mizuno R, Hanyuu N, Iwabuchi S,

Yanaga $\mathrm{K}$ : Intraoperative thermal imaging in esophageal replacement: its use in the assessment of gastric tube viability. Surg Today. 2006 ; 36(9) : 802-6 
16. Kitai T, Inomoto T, Miwa M, Shikayama T : Fluorescence navigation with indocyanine green for detecting sentinel lymph nodes in breast cancer.

Breast Cancer. 2005 ; 12(3) : 211-5.

17. Parungo CP, Ohnishi S, Kim SW, Kim S, Laurence RG, Soltesz EG, Chen FY, Colson YL, Cohn LH, Bawendi MG, Frangioni $\mathrm{JV}$ : Intraoperative identification of esophageal sentinel lymph nodes with near-infrared fluorescence imaging. J Thorac Cardiovasc Surg. 2005 Apr ; 129(4) : 844-50.

18. Kusano M, Tajima Y, Yamazaki K, Kato M, Watanabe M, Miwa M. : Sentinel node mapping guided by indocyanine green fluorescence imaging : a new method for sentinel node navigation surgery in gastrointestinal cancer. Dig Surg. 2008; 25(2) : 103-8.

19. Tajima Y, Yamazaki K, Masuda Y, Kato M, Yasuda D, Aoki T, Kato T, Murakami M, Miwa M, Kusano M : Sentinel node mapping guided by indocyanine green fluorescence imaging in gastric cancer. Ann Surg. 2009 Jan ; 249(1) : 58-62

20. Yamashita S, Tokuishi K, Miyawaki M, Anami K, Moroga T, Takeno S, Chujo M, Yamamoto S, Kawahara K : Sentinel node navigation surgery by thoracoscopic fluorescence imaging system and molecular examination in non-small cell lung cancer. Ann Surg Oncol. 2012 Mar ; 19(3) : 728-33.

21. Ishizawa T, Masuda K, Urano Y, Kawaguchi Y, Satou S, Kaneko J, Hasegawa K, Shibahara J, Fukayama M, Tsuji S, Midorikawa Y, Aburatani H, Kokudo N : Mechanistic background and clinical applications of indocyanine green fluorescence imaging of hepatocellular carcinoma. Ann Surg Oncol. 2014 Feb ; 21(2) : 4408

22. Ishizawa T, Fukushima N, Shibahara J, Masuda K, Tamura S, Aoki T, Hasegawa K, Beck Y, Fukayama M, Kokudo N : Realtime identification of liver cancers by using indocyanine green fluorescent imaging. Cancer. 2009 Jun 1; 115(11) : 2491-504

23. Morita Y, Sakaguchi T, Unno N, Shibasaki Y, Suzuki A, Fukumoto K, Inaba K, Baba S, Takehara Y, Suzuki S, Konno $\mathrm{H}$ : Detection of hepatocellular carcinomas with near-infrared fluorescence imaging using indocyanine green : its usefulness and limitation. Int J Clin Oncol. 2013 Apr ; 18(2) : 232-41

24. Watanabe M, Tsunoda A, Narita K, Kusano M, Miwa M : Colonic tattooing using fluorescence imaging with light-emitting diode-activated indocyanine green : a feasibility study. Surg Today. 2009 ; 39(3) : 214-8.

25. Noura S, Ohue M, Seki Y, Tanaka K, Motoori M, Kishi K, Miyashiro I, Ohigashi H, Yano M, Ishikawa O, Miyamoto Y : Feasibility of a lateral region sentinel node biopsy of lower rectal cancer guided by indocyanine green using a near-infrared camera system. Ann Surg Oncol. 2010 Jan ; 17(1) : 144-51

26. Nitori N, Deguchi T, Kubota K, Yoshida M, Kato A, Kojima M, Kadomura T, Okada A, Okamura J, Kobayashi M, Sato T, Beck Y,
Kitagawa Y, Kitajima M.: Successful treatment of non-occlusive mesenteric ischemia (NOMI) using the Hyper Eye Medical System TM for intraoperative visualization of the mesenteric and bowel circulation : report of a case. Surg Today. 2014 Feb ; 44(2) : 359-62

27. Handa T, Katare RG, Nishimori H, Wariishi S, Fukutomi T, Yamamoto M, Sasaguri S, Sato T: New device for intraoperative graft assessment: Hyper Eye charge-coupled device camera system. Gen Thorac Cardiovasc Surg. 2010 Feb ; 58(2) : 68-77

28. Yamamoto M, Sasaguri S, Sato T : Assessing intraoperative blood flow in cardiovascular surgery. Surg Today. 2011 Nov ; 41(11) : 1467-74

29. Hida J, Yasutomi M, Maruyama T, Fujimoto K, Nakajima A, Uchida T, Wakano T, Tokoro T, Kubo R, Shindo K : Indication for using high ligation of the inferior mesenteric artery in rectal cancer surgery. Examination of nodal metastases by the clearing method. Dis Colon Rectum. 1998 Aug ; 41(8) : 984-7

30. Nano M, Dal Corso H, Ferronato M, Solej M, Hornung JP, Dei Poli M : Ligation of the inferior mesenteric artery in the surgery of rectal cancer : anatomical considerations. Dig Surg. $2004 ; 21(2): 123-6$

31. Goligher JC : The adequacy of the marginal blood-supply to the left colon after high ligation of the inferior mesenteric artery during excision of the rectum. Br J Surg. 1954 Jan ; 41(168) : 3513 .

32. Morgan CN, Griffiths JD : High ligation of the inferior mesenteric artery during operations for carcinoma of the distal colon and rectum. Surg Gynecol Obstet. 1959 Jun ; 108(6) : 641-50.

33. Kashiwagi H, Konishi F, Furuta K, Okada M, Saito Y, Kanazawa $\mathrm{K}$ : Tissue blood flow of the sigmoid colon for safe anastomosis following ligation of the inferior mesenteric artery. Nihon Geka Gakkai Zasshi. 1994 Aug ; 95(8) : 504-11.

34. Dworkin MJ, Allen-Mersh TG : Effect of inferior mesenteric artery ligation on blood flow in the marginal artery dependent sigmoid colon. J Am Coll Surg. 1996 Oct ; 183(4) : 357-60.

35. Seike K, Koda K, Saito N, Oda K, Kosugi C, Shimizu K, Miyazaki M.:Laser Doppler assessment of the influence of division at the root of the inferior mesenteric artery on anastomotic blood flow in rectosigmoid cancer surgery. Int $\mathrm{J}$ Colorectal Dis. 2007 Jun ; 22(6) : 689-97.

36. Corder AP, Karanjia ND, Williams JD, Heald RJ : Flush aortic tie versus selective preservation of the ascending left colic artery in low anterior resection for rectal carcinoma. Br J Surg. $1992 \mathrm{Jul} ; 79(7): 680-2$.

37. Lange MM, Buunen M, van de Velde CJ, Lange JF : Level of arterial ligation in rectal cancer surgery: low tie preferred over high tie. A review. Dis Colon Rectum 2008 ; 51 : 1139-1145 